УДК 316.42 (512.36)

БАДАРАЕВ Дамдин Доржиевич - кандидат социологических наук, доцент; старший научный сотрудник Института монголоведения, буддологии и тибетологии СО РАН (670047, Россия, Республика Бурятия, г. Улан-Удэ, ул. Сахьяновой, 6; damdin80@таil.ru)

\title{
ДЕМОГРАФИЧЕСКАЯ ДИНАМИКА И МОДЕРНИЗАЦИОННЫЕ ИЗМЕНЕНИЯ В СИСТЕМЕ ЖИЗНЕОБЕСПЕЧЕНИЯ МОНГОЛЬСКОГО ОБЩЕСТВА
}

\begin{abstract}
Аннотация. В статье рассматривается сравнительная динамика демографических показателей в предкризисные 2007 и 2019 гг. и связанные с ними модернизационные процессы в системе жизнеобеспечения Монголии. Согласно данным статистики, отмечается положительная тенденция в инфраструктурных сферах - энерго- и водоснабжении и ЖКХ; позитивные изменения наблюдаются в отраслях образования, здравоохранения и информационных технологий. Проблемные зоны, касающиеся безработицы и бедности, также подтверждаются результатами социологического исследования. Данные исследования демонстрируют позитивные изменения в стратификации общества: расширяются срединные слои, улучшается материальная обеспеченность населения. К базовым ценностям в современном монгольском обществе относятся дом, семья и здоровье.
\end{abstract}

Ключевые слова: демографические показатели, модернизация, система жизнеобеспечения, Монголия, ценности

$\mathbf{Y}$ ровень социального благополучия населения и система жизнеобеспечения в обществе представляют исследовательский интерес ввиду неустойчивости социально-экономического положения многих стран на современном этапе. Согласно статистическим данным, ВВП Монголии после стремительного экономического подъема в 2011 г. (до 17,3\%) в дальнейшем начал так же стремительно меняться в результате последующих кризисных колебаний, достигнув в конце 2016 г. показателя 1,2\%, а в конце допандемийного 2019 г. - 5,1\%. В ковидном 2020 г. для Монголии, как и для многих других стран, были характерны отрицательные показатели ВВП: в I квартале $-10,7 \%$, a в IV квартале $-5,3 \%$. Пандемийный период требует отдельного изучения в связи с выраженным воздействием на экономику страны особого глобального фактора - COVID-19. В этой связи исследовательские предположения связаны с неоднозначной корреляцией между неустойчивым ВВП Монголии и показателями социального самочувствия населения и социального благополучия монгольского общества.

В основу показателей социального благополучия монгольского общества можно включить широкий перечень демографических индикаторов, представленных в докризисные годы, которые предшествовали экономическим кризисам 2008-2009 гг. и 2020-2021 гг. За рассматриваемый период в Монголии произошли существенные изменения в демографической сфере.

Так, за 2007-2019 гг. численность населения увеличилась на 25,8\%, с чем связаны позитивные изменения и в других показателях: улучшились показатели рождаемости и смертности населения, средней продолжительности жизни, трудовых ресурсов - занятости и безработицы, сельской бедности, возросла плотность населения. Наиболее значимые изменения связаны с показателями урбанизации населения Монголии: за указанный период городское население увеличилось на $36,4 \%$, а численность столичных жителей - на 40,1\%. Такие 
Таблица 1

Сравнительная динамика демографических показателей Монголии в 2007 и 2019 гг.

\begin{tabular}{|l|c|c|}
\hline \multicolumn{1}{|c|}{ Показатели } & $\mathbf{2 0 0 7}$ & $\mathbf{2 0 1 9}$ \\
\hline Численность населения, тыс. чел. & 2620,5 & 3296,8 \\
\hline Плотность населения на 1 км & 1,7 & 2,1 \\
\hline Городское население, тыс. чел. & 1655,5 & 2258,9 \\
\hline Сельское население, тыс. чел. & 965,0 & 1037,8 \\
\hline Численность населения г. Улан-Батора, тыс. чел. & 1098,8 & 1539,8 \\
\hline Экономически активное население, тыс. чел. & 1013,4 & 1268,6 \\
\hline Экономически неактивное население, тыс. чел. & 588,2 & 832,2 \\
\hline Занятые, уровень занятости, тыс. чел. / доля рабочей силы, \% & $899,0 / 54,5$ & $1176,0 / 54,4$ \\
\hline Безработные, уровень безработицы, тыс. чел. /\% & $114,5 / 11,3$ & $92,6 / 7,3$ \\
\hline Зарегистрированные безработные, тыс. чел. & 29,9 & 28,7 \\
\hline Уровень бедности, в т.ч.,\% & 35,2 & 28,4 \\
\hline городское население & 26,9 & 27,2 \\
\hline сельское население & 46,6 & 30,8 \\
\hline Уровень смертности на 1 000 чел.,\% & 6,2 & 5,6 \\
\hline Уровень рождаемости на 1000 чел.,\% & 21,8 & 24,4 \\
\hline Уровень заключения браков на 1 000 чел.,\% & 24,5 & 9,8 \\
\hline Уровень разводов на 1 000 чел.,\% & 1,1 & 2,1 \\
\hline Средняя продолжительность жизни, лет, в т.ч., лет & 66,54 & 70,41 \\
\hline мужчины & 63,13 & 66,38 \\
\hline женщины & 70,23 & 75,96 \\
\hline
\end{tabular}

Источник: Статистикийн мэдэллийн нэгдсэн сан [Единый фонд статистической информации]. - Сайт Национального статистического комитета Монголии. Доступ: http://www.1212.mn/stat.aspx?LIST_ID=976_L18 (проверено 02.09.2021).

изменения обусловлены рядом объективных факторов, в т.ч. ростом качественных показателей систем жизнеобеспечения. Несмотря на некоторые улучшения, к негативным данным в социально-экономической сфере можно отнести высокие показатели общей и регистрируемой безработицы, уровня бедности, особенно городской. Особого внимания требует трансформация семейнобрачных отношений и ценностных основ семьи: за рассматриваемый период наблюдается резкое падение уровня заключения браков - в 2,5 раза и рост уровня разводов почти в 2 раза. С такими динамическими демографическими и ценностными изменениями монгольское общество прошло временной промежуток между предкризисными 2007 и 2019 гг.

Предполагается, что позитивная демографическая динамика обусловлена развитием системы жизнеобеспечения в стране за последние десятилетия [Нийгмийн шинэчлэл... 2001]. Под системой жизнеобеспечения общества подразумевается комплекс условий, обеспечивающих комфортную и приемлемую среду для проживания и полноценной жизнедеятельности граждан и способствующих нормальному развитию и функционированию общества и его институтов. 
К важнейшим показателям системы жизнеобеспечения можно отнести ряд инфраструктурных индикаторов в сферах электроснабжения, водоснабжения, а также обеспеченности семей и домохозяйств благоустроенным жильем. Кроме того, к базовым отраслям удовлетворения основных конституционных прав и свобод граждан относятся здравоохранение, образование и информационные технологии и услуги связи. К числу сводных индикаторов социального благополучия, принятых международным сообществом, относится индекс человеческого развития (ИЧР). Индекс человеческого развития Монголии, по данным 2019 г., составил 0,744. Этот индекс определяется как среднеарифметическая сумма трех показателей - ожидаемой продолжительности жизни $(0,766)$, уровня грамотности населения $(0,726)$ и уровня жизни населения / ВВП на 1 чел. $(0,732)$. За последние годы в Монголии намечается тенденция постепенного роста ИЧР: в 2013 г. он составлял 0,726, в 2016 г. - 0,734. Путем анализа данных, представленных на сайте Национального статистического комитета Монголии, можно продемонстрировать масштабы изменения основных инфраструктурных сфер и отраслей за 2010-2020 гг.

По показателю электроснабжения домохозяйств в Монголии за последние десять лет произошли позитивные изменения. Так, централизованным электроснабжением охвачены 732494 домохозяйства в 2020 г. против 548517 в 2010 г. Оборудованием для возобновляемых источников электроэнергии в 2020 г. пользуются 151999 семей, тогда как в 2010 г. таковых было 110200. За последнее десятилетие уменьшилось число домохозяйств, пользующихся электроэнергией, производимой дизельными электростанциями, с 18905 до 450, малогабаритными электростанциями - с 12548 до 7 667. Но в то же время в 2020 г. оставались без источников электроснабжения еще 4817 монгольских семей, из которых 1046 проживают в пригородах Улан-Батора. Проблема электрификации домохозяйств остается приоритетной задачей для власти Монголии, которая характеризуется низкой плотностью населения, урбанизацией территории и центростремительной миграцией в направлении столицы - Улан-Батора.

По водоснабжению в Монголии также произошли существенные положительные сдвиги. За 2010-2020 гг. центральным и автономным водоснабжением обеспечены 262835 домохозяйств; рост по сравнению с 2010 г. составил 57,8\%. Наибольший рост показателей водоснабжения произошел в г. Улан-Баторе - с 116233 семей в 2010 г. до 194683 в 2020 г. В целом по стране наибольший рост показателей водоснабжения домохозяйств достигнут за счет обеспечения безопасных колодцев и источников: с 117117 домохозяйств в 2010 г. до 378539 в 2020 г., из которых 166412 - домохозяйства Улан-Батора. Проблема обеспечения населения чистой водой и водопоями для многотысячных стад домашних животных также остается одним из приоритетов для страны. Достижения последнего десятилетия демонстрируют возможности дальнейшего совершенствования системы водоснабжения в Монголии.

Численность монгольских домохозяйств, обеспеченных благоустроенным и полностью обеспеченным инженерными сетями жильем также за десятилетие показала значимые результаты: с 382808 в 2010 г. до 546634 в 2020 г., причем большую часть из них составляют домохозяйства Улан-Батора - 317799. Однако в целом по стране также выросло и число домохозяйств с неблагоустроенным жильем - 284806 в 2020 г. против 244263 в 2010 г., при этом 123035 из них составляют домохозяйства Улан-Батора.

За 2010-2020 гг. также претерпела изменения и система здравоохранения Монголии. Анализ данных статистики показывает, что наметилась устойчивая тенденция увеличения числа медицинских учреждений, койко-мест в них, 
числа врачей и медицинских сестер. Общее число койко-мест в 2019 г. составило 25 661, из которых 13315 - в Улан-Баторе. Количественный прирост за 10 лет составил 44\% (17 821 койко-мест в 2010 г.). За последние 5 лет число медицинских учреждений всех типов увеличилось с 3100 объектов в 2015 г. до 4459 в 2019 г., из которых 2689 расположены в Улан-Баторе (в 2015 г. их число составляло 1 612). За 2010-2019 гг. общее число врачей выросло с 7497 чел. до 11 788, из которых 7263 чел. трудятся в Улан-Баторе. Загруженность медицинских сестер постепенно снижается - с 298 на 1 чел. в 2010 г. до 250 чел. в 2019 г. В Улан-Баторе этот показатель снизился с 278 до 214 соответственно.

Система образования Монголии за 2010-2019 гг. также существенно преобразовалась в количественном отношении: в 2019 г. число детских садов составило 1 439, тогда как в 2010 г. - 839, в Улан-Баторе - 685 и 266 соответственно. Число детей, посещающих дошкольные образовательные учреждения, в 2019 г. составило 263333 чел., тогда как в 2010 г. их было 157181 чел. Статистика по средним общеобразовательным школам Монголии также демонстрирует положительную динамику за указанный период: 820 и 751 соответственно; по Улан-Батору - 257 и 206 соответственно. В них обучались в 2019 г. 640449 детей, тогда как в 2010 г. число школьников составляло 512213 чел. Учреждения высшего образования Монголии претерпевают изменения, связанные с высокой конкуренцией, закрытием и объединением некоторых профессиональных учреждений. Так, за 2010-2019 гг. число учреждений высшего образования уменьшилось со 113 до 95, при этом у некоторых учреждений произошла смена форм собственности: число государственных вузов составило 21 (в 2010 г. их было 16). Число частных вузов, наоборот, снизилось - с 92 до 71, а зарубежных вузов - с 5 до 3. Соответственно, наблюдается тенденция уменьшения числа студентов профессиональных высших учебных заведений со 170126 чел. в 2010 г. до 148446 чел. в 2019 г.

В век развития информационных технологий большое значение для современного общества имеют показатели распространения стационарной и сотовой связи, а также персональных компьютеров. По сравнению с 2010 г. в 2019 г. число стационарных телефонов в Монголии увеличилось в 2,5 раза - с 143193 до 355 060. Степень активного пользования сотовой связью демонстрирует показатель числа активных сим-карт - 4 418,9 тыс. шт., что более чем на 1 млн ед. превышает численность всего населения страны. За 2019 г. в Монголии зарегистрированы 925199 пользователей кабельного телевидения, на 1000 чел. приходилось 208 компьютеров, тогда как в 2010 г. - 136.

Вместе с тем, помимо статистических данных социальной практики, реальную картину монгольского общества можно уточнить при помощи результатов социологических замеров с целью выявления субъективных взглядов представителей разных слоев населения на их социальное самочувствие, оценки социально-экономического положения семей и индивидов, определения ценностной сферы и др. [Цэцэнбилэг 2002; Уртнасан 2017].

В рамках данной статьи представлены результаты социологического исследования «Процессы социальной интеграции и дезинтеграции в трансформирующихся обществах России и Монголии» 1 .

1 Исследование было проведено в Монголии в 2015-2016 гг. по квотной стратифицированной выборке численностью 829 чел., определенной по полу, возрасту, национальности и месту жительства. Исследование осуществлено группой социологов Института философии Академии наук Монголии, Института социологии ФНИСЦ РАН и Института монголоведения, буддологии и тибетологии СО РАН. Места проведения исследования: столица г. Улан-Батор и его городские районы - Баянгол, Баянзурх, Сонгинохайрхан, Сухбаатар, Хан-Уул, Чингэлтэй, а также Хубсугульский, Араханганский, Дарханский, Орхонский и Кобдосский сельские аймаки. 
В современных условиях материально-экономической детерминантности уровня жизни населения представляется важным дифференцирование населения Монголии по уровню доходов [Грайворонский 2017: 144]. Согласно такой стратификации, семьи, которые кое-как сводят концы с концами, составили в монгольском обществе 2,4\%. Семьи с доходами, обеспечивающими только питание, но не достаточными для покупки одежды, составили 14,8\%. Питание и недорогую одежду могут себе купить четверть респондентов - 25,1\%, но средств у них недостаточно для покупки бытовой техники. Доходы, не способные обеспечить покупку автомобиля, имеют $36,7 \%$ респондентов. Семьи с доходами, позволяющими приобрести автомашину, но недостаточными для приобретения квартиры, составили 16,4\%. Верхушку монгольского общества составляют представители богатого слоя, таковых среди опрошенных оказалось 4,6\%. Они без труда могут себе позволить приобрести машину и квартиру. В отличие от всех других слоев, они ни в чем себе не отказывают, могут при желании приобрести практически любую недвижимость, кроме элитного жилья.

В условиях свободного рынка доходы монголов пополняются из разных источников. Статистические данные демонстрируют следующую структуру доходов граждан Монголии: 80,3\% занимают денежные доходы, 6,8\% - доходы, полученные в дар от других лиц, 12,9\% - доходы от ведения домашнего хозяйства. В структуре денежных доходов заработок составляет $30,6 \%$, социальные выплаты и пенсии - 17,9\%, доходы от ведения семейного бизнеса и предпринимательства $-24,4 \%$, прочее $-7,4 \% 1$.

По данным социологического исследования, в структуре доходов монгольских респондентов показаны такие нестандартные источники, как «доходы от вложений в месторождения природных богатств» - 3,6\% и «денежные переводы от родственников, работающих за рубежом» - 5\%. Последние, несмотря на незначительный объем, имеют достаточно важное значение для их получателей. Обеспеченность населения социальными выплатами выглядит следующим образом: 67,8\% опрошенных указали, что они сами и члены их семей получают пенсию по возрасту, 10,5\% - пенсию по инвалидности, 9,5\% - детские пособия и т.д. Результаты исследования показывают, что система социальной защиты в Монголии характеризуется достаточно широким охватом массовых слоев социально незащищенных категорий населения.

По данным исследования, более половины населения располагают доходами ниже прожиточного минимума и, соответственно, могут быть отнесены к категории бедных. Имеющиеся доходы монгольских респондентов явно не устраивают их, запросы жителей говорят о стремлении опрошенных зарабатывать больше, что в действительности требует приложения существенных усилий не только со стороны работников, но и со стороны органов власти. Необходимо создавать соответствующие условия и новые рабочие места в отраслях экономики страны.

О степени материальной обеспеченности опрошенных монгольских респондентов можно судить по данным исследования. В структуре материальной обеспеченности у 65,5\% респондентов есть свой компьютер, 60,9\% проживают в благоустроенной квартире, 52,4\% имеют свой автомобиль, а 33,1\% - дачу и собственный дом.

При выявлении степени удовлетворенности монгольских респондентов разными сторонами их жизнедеятельности превалируют в основном такие

1 Монгол улсын статистикийн эмхэтгэл - 2016 [Статистический ежеггодник Монголии 2016]. Уланбаатар. 2017. С. 94. 
варианты, как «скорее удовлетворен» и «отчасти удовлетворен, отчасти нет». Анализ данных исследования показывает, что по сумме утвердительных ответов наилучшим образом дела обстоят в сфере отношений с детьми и близкими $(69,6 \%)$, брака и семейных отношений $(64,4 \%)$, а также питания $(57,4 \%)$. По сумме негативных оценок «скорее не удовлетворен» «совсем не удовлетворен» выделяются такие варианты, как «возможность профессионального и карьерного роста» $(25,6 \%)$ и «условия труда» $(20,8 \%)$.

По субъективной самоидентификации респондентов можно представить модель социальной стратификации монгольского общества. По форме модель напоминает приземистую крону дерева с широкими ветками ближе к средней части с резким сужением вытянутой кроны в верхней части.

Данные статистики и исследования демонстрируют наличиие в обществе многочисленных социально не защищенных и малообеспеченных слоев населения. Анкетные данные показывают, что основные причины сложившейся ситуации связаны с высоким уровнем бедности в стране. Участники исследования обвиняют в росте бедности действующие власти, которые способствуют обогащению одних и разорению других $(54,9 \%)$. На втором месте указаны низкий размер заработной платы и падение ценности труда $-51,8 \%$. На третьем месте с примерно одинаковым числом упоминаний выбраны респондентами «нежелание работать и лень» $(35,9 \%)$ и «нерешительность и пассивность населения» $(35,6 \%)$. Такие причины, как состояние здоровья, возможности получения хорошего образования, боязнь риска, упоминаются респондентами крайне редко. Таким образом, в числе основных причин роста бедности в обществе указываются внешние, не зависящие от граждан причины, связанные с политикой властей и недостаточностью возможностей для трудовой деятельности. После этого следуют причины внутреннего плана, связанные с субъективными характеристиками граждан.

Для монгольского общества характерны наиболее распространенные общечеловеческие ценности. По частоте упоминания на ведущих позициях находятся такие ценности, как «дом и семья» $(89,3 \%)$, «здоровье» $(85,7 \%)$. Далее следуют «образованность, духовность, высокая культура» $(46,8 \%)$, на 4-м месте расположилась «материальная обеспеченность» $(35,5 \%)$, на 5-м месте - «чувство безопасности» $(30,4 \%)$. Наименее упоминаемыми стали «независимость, свобода» $(13,3 \%)$ и «общественное признание, уважение других» $(14,4 \%)$. Следовательно, тремя наиболее значимыми ценностями в современном монгольском обществе являются дом, семья и здоровье.

Таким образом, современное монгольское общество за последние десятилетия претерпело динамичные демографические изменения, что связано с модернизацией системы жизнеобеспечения в стране в области электроснабжения, водоснабжения, обеспечения качественным жильем. Позитивные сдвиги отмечаются в отраслях образования, здравоохранения, информационных технологий, что подтверждается постепенным ростом ИЧР в Монголии, а также результатами социологических исследований, которые фиксируют рост материального благополучия монголов, формирование срединных слоев в стратификационной структуре монгольского общества. Несмотря на статистические показатели ухудшения в сфере браков и разводов, наибольшая удовлетворенность выражена у монголов именно в сфере семейно-брачных отношений и рациона питания, тогда как больше всего они не удовлетворены уровнем доходов, возможностью профессионального и карьерного роста и условиями труда. На достаточно высоком уровне остаются показатели безработицы и бедности в стране, в чем население обвиняют власти страны. Система социальной защиты населения направлена на широкий охват различных слоев населения, соци- 
альные выплаты имеют важнейшее значение для доходов семей независимо от их размера. При существующих кризисных экономических колебаниях и характерных тенденциях демографического прироста и совершенствования системы жизнеобеспечения монгольского общества возможен дальнейший рост ИЧР Монголии.

Статья подготовлена в рамках государственного задания (проект «Россия и Внутренняя Азия: динамика геополитического, социально-экономического $и$ межкультурного взаимодействия (XVII - XXI вв.)», № 121031000243-5).

\section{Список литературы}

Грайворонский В.В. 2017. Монголия в начале XXI в. (политика, экономика, общество). М.: Изд-во ИВ РАН. 352 с.

Нийгмийн шинэчлэл: амьдралын хэв маягийн оорчлолт [Модернизация общества и изменение стиля жизни]. 2001. Улан-Батор. 207 с.

Уртнасан Ц. 2017. Монголын нийгмийн бутииин судалгаа шинжилгээ [Исследование социальной структуры Монголии]. Улан-Батор. 363 с.

Цэцэнбилэг Ц. 2002. Проблемы модернизации монгольского общества. УланБатор. 148 с.

BADARAEV Damdin Dorzhievich, Cand.Sci. (Soc.), Associate Professor, Senior Research Associate of the Institute for Mongolian, Buddhist and Tibetan Studies, Siberian Branch of Russian Academy of Sciences (6 Sakhyanovoj St, UlanUde, Republic of Buryatia, Russia, 670047; damdin80@mail.ru)

\section{DEMOGRAPHIC DYNAMICS AND MODERNIZATION CHANGES IN THE LIFE SUPPORT SYSTEM OF MONGOLIAN SOCIETY}

Abstract. The article examines the comparative dynamics of demographic indicators in the pre-crisis years of 2007 and 2019 and related modernization processes in the life support system of Mongolia. According to statistics, there is a positive trend in the infrastructure spheres of energy and water supply and housing and communal services, positive changes are observed in the sectors of education, health care and information technologies. The problem areas related to unemployment and poverty are also confirmed by the results of sociological research. These studies also demonstrate positive changes in the stratification of society, the middle strata are expanding, and the material security of the population is improving. The basic values in modern Mongolian society are home, family and health.

Keywords: demographic indicators, modernization, life support system, Mongolia, values 